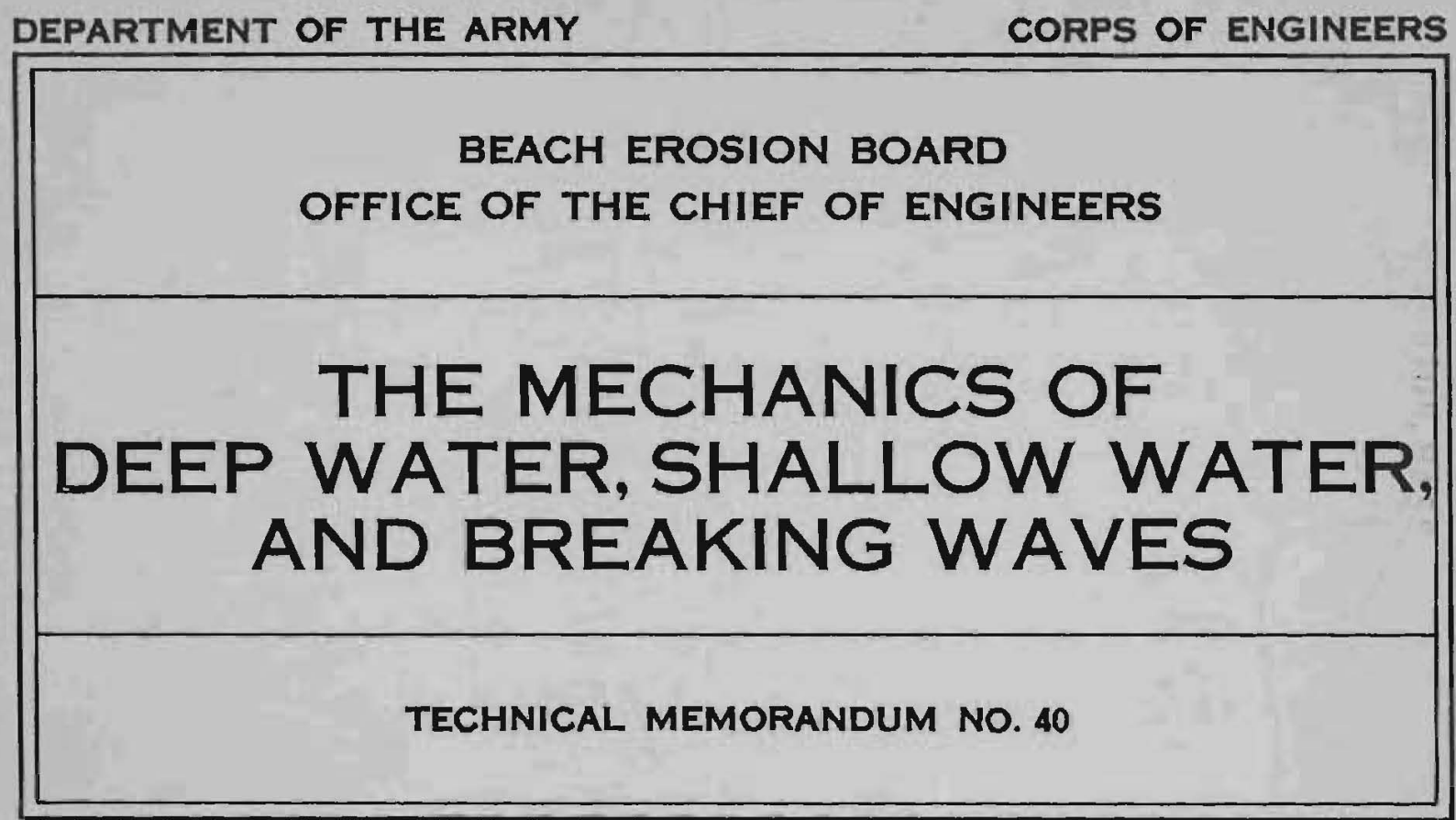




\title{
THE MECHANICS OF DEEP WATER, SHALLOW WATER, AND BREAKING WAVES
}

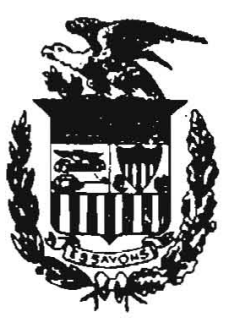 \\ TECHNICAL MEMORANDUM NO. 40 \\ BEACH EROSION BOARD \\ CORPS OF ENGINEERS
}




\section{FOREWORD}

Little experimental data exist on the paths and velocities of water particles within waves in very shallow depths and at breaking. Douglas Johnson in his "Shore Processes and Shoreline Development" (1919), and many writers since and perhaps before, have discussed the velccity differential under the crests and troughs of waves in shallow water as an explanation of the sediment sorting and slope adjustment on beach and nearshore slopes. The very substantial departure from theory found in depths less than one tenth of the wave length in the report which follows, with results indicating velocity differential in the order of 2 to 1 favoring the direction of wave propagation (for waves of low steepness) is an important factor in the explanation of shore processes.

This report was prepared at the University of California in pursuance of a research program sponsored by the Office of Naval Research. Messrs. Jack R. Morison and R. C. Crooke, authors of the report, were assisted by H. E. Chamberlain, W. L. Erdman, R. D. Costello, E. K. Rice, D. M. Nelson, M. J. Larrocco, F. E. Mead, M. M. Lincoln, C. M. Lamont and M. E. Conklin, in the preparation of the report. The research program was under general supervision of Professor J. W. Johnson. Because of its applicability to the research and investigation program of the Beach Erosion Board, the report is published at this time in the technical memoranda series. Views and conclusions stated in the report are not necessarily those of the Beach Erosion Board.

This report is published under authority of Public Law 166, 79th Congress, approved July 31, 1945. 
Abstraat - Experimental data are presented for doep water, shallow water, ana breaking waves with respect to the wave surface time history, the horizontal and vertioal partiole velocities and the particle orbits. The measurements are compared where applioaple to Stokes wave theory. The results are that the Stokes wave theory $(1,2,3,4) *$, and other wave theories $(2,3,4)$, show good agreement with the measurements for deep weter oonditions and even to $d / L$ values of approximately 0.2. The theories do not apply for shallow water oonditions where $d / \mathrm{h}$ values are appreciably less than 0.2 and the waves have an appreolable steepness.

Introduotion - The purpose of this report is to present experimental date on the mechanios of wares and to compare these data with the Stokes wave theory $(1,2,3,4)$. The ware surface time history, horizontal and vertioal partiole volooities and the partiole orbit were measured in deep water, shallow water, and for brealdng waves. The Stokes theory showed good agreement with the measurements for oonditions where $d / L$ was greater than about 0.2 . For shallow water waves (d/L appreo1ably less than 0.2) of appreoiable steepness and for breaking waves on sloping beaohes, the Stokes theory to the second approximation shows poor agreoment. It was found that steep wares near the breaking point on a stoep beaoh will show oloser agreement with the Stokes theory than low wares on a flat beach. The surface time history at the point of breaking shows olose agreement with the space profile at a distance of $20 \%$ of the wave length on either side of the breaking polnt. The greatest horizontal partiole velocity occurs when a wave breaks, but there is no evidence that any particles approach the wave velooity exoept the particles at the orest of the breaking wave. The greatest vertioal velooity oocurs in an upward direotion, just as the wave breaks. For unbroken waves that are asymetrical about the crest, the greatest vertical velocity occurs in an upward direotion, just as the wave orest approaches the partiole. Extremely shallow water waves in a channel form a second wave that travels at a slower velocity than the original wave, thus forming waves that do not have a permanent form. The particle orbit of this wave train consists of an ellipse within an ellipse if the seoond wave is in the trough of the original wave. Ho mass transport studies were attempted because of unknown tank effects.

Experiments - The experiments were conducted in the $1 \mathrm{ft}$. by $3 \mathrm{ft}$ by $60 \mathrm{ft}$. wave channel in the Fuid Moohanios Laboratory, Onfversity of California, Berkeloy. A mixture of carbon tetrachloride, xylene (xylol) and zino oxide was mado, whioh had the same speoifio gravity as watss. Droplets were injected into the water and the resulting motion was photographed through the glass sides of the ohannel with a motion ploture comera. A clock and grid wore placed in the field of view in order to obtain time and spaoe .ooordinates. The motion piotures were analyzed frame by frame to obtain the data presented. The particle orbits for the deepwater and shallow-water waves were adjusted so that the apparent mass transport was eliminated. This was done by measuring the apparent mass transport over one wave oyole and apportioning the negative of this motion linearly over the particle path for one wave oyole. During all experiments with unbroken waves, the waves were made as steөp as possiblo.

* Supersoript numbers in parentheses refer to references at end of report 
Flrst and Seoond Approximations of Stokes Ware Theorys The first and seoond approximations of Stokes wave theory were oompared with the measured wave surfaoe time history, horizontal and vertioal particle velocity and the partiole path.

The seoond approximation of Stokes wave theory for the wave profile $(1,2)$ is given by the expression

$$
\frac{s}{d}=1+\frac{B}{2 d}\left\{\cos \frac{2 \pi \bar{x}}{L}+\frac{\pi H}{2 L}\left[\frac{\operatorname{Cosh} \frac{2 \pi d}{L}\left(\operatorname{Cosh} \frac{4 \pi d}{L}+2\right)}{2\left(\operatorname{Sinh} \frac{2 \pi d}{L}\right)^{3}}\right] \operatorname{Cos} \frac{4 \pi \bar{x}}{L}\right\}
$$

where

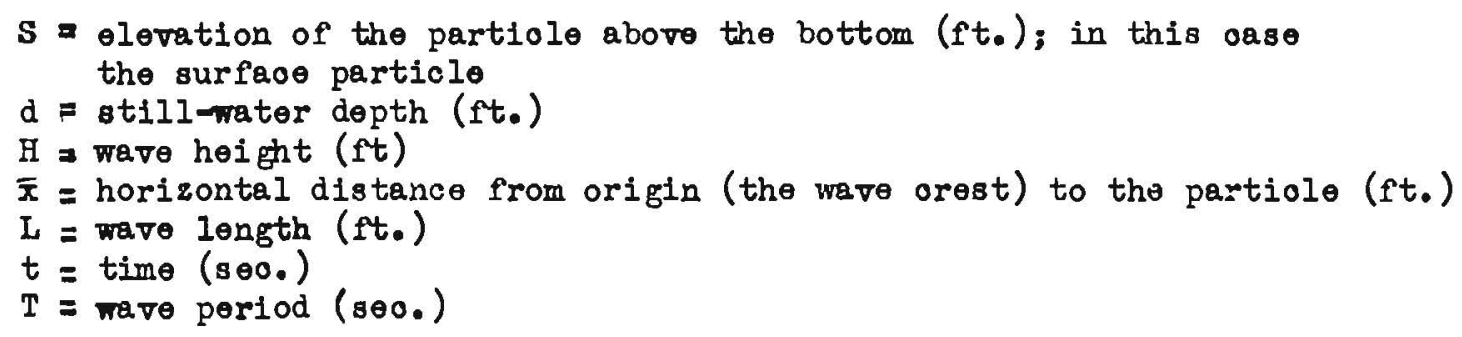

Equation (1) becomes the surface time history by replaoing $\bar{x} / \mathrm{h}$ with $t / T$ whioh is possible for waves of permanent form. This was the only theory used for oomparison with the measured surfeoe time history beoause the troohgidal surfaoe time history $(3,4)$ and Stokes' deep water surface time history $(1)$, all agree olosely with each other and with the measured surfece time history for deep water. In shallow water the previously mentioned expressions for the surfaoe time history do not agree with each other nor with the experimental results. Furthermore, the third approximation of Stokes wave theory will only slightly improve the situation. The writer believes it would take many approximations to extend the Stokes were theory to waves of appreciable steopness in very shallow water.

The first approximation (Stokes) to the horizontal partiole velooity(1) is given by the expression

$$
u=\frac{\pi E}{T} \frac{\operatorname{Cosh} \frac{2 \pi S}{L}}{\operatorname{Sinh} \frac{2 \pi d}{L}} \operatorname{Cos} \theta
$$

where

$$
\begin{aligned}
u= & \text { horizontel partiole velocity, (ft. per seo.) } \\
\theta= & \text { angular position of particle in its orbit measured counterolookwise } \\
& \text { and where there is no mass transport, (degrees) }
\end{aligned}
$$

The use of $\theta$ is a modification of the Stokes equation whioh includes the assumption that the horizontal particle velooity is zero at the mean vertioal partiole position. The use of $\theta$ applies only for the first approximation. 
The second approximation (Stokes) of the horizcntal particle velocity $(1,2)$ is given by the expression

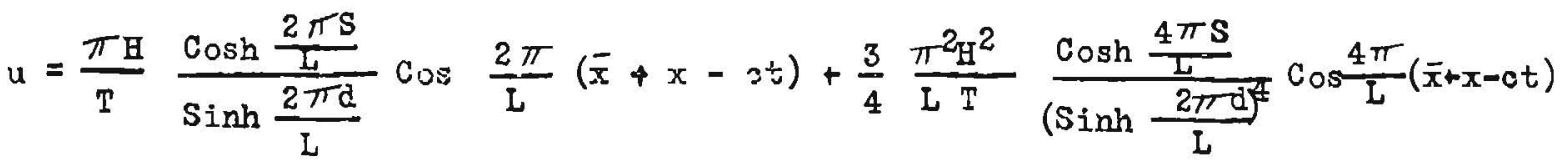

where
$x=$ horizontal position of particle in its mean horizontal position (ft).
$c=$ wave velocity of propagation, (ft/seo)

The particle velosity under the crest becomes

$u($ crest $)=\frac{\pi H}{T} \frac{\operatorname{Cosh} \frac{2 \pi S}{I}}{\operatorname{Sinh} \frac{2 \pi d}{L}}+\frac{3}{4} \frac{\pi^{2} H^{2}}{L} \frac{\operatorname{Cosh} \frac{4 \pi S}{L}}{\left(\operatorname{Sinh} \frac{2 \pi d}{L}\right)^{4}}$

and the particle velocity under the trough beoomes

$$
u(\text { trough })=\frac{-\pi H}{T} \frac{\cosh \frac{2 \pi S}{L}}{\sinh \frac{2 \pi d}{L}}+\frac{3}{4} \frac{\pi^{2} H^{2}}{L T} \frac{\cosh \frac{4 \pi S}{L}}{\left(\sinh \frac{2 \pi d}{L}\right)^{4}}
$$

The absolute values of $u$ (erest) and $u$ (trough) and the maximum value of Equation (2) were compared to the measured horizontal partiole velocities under the crest and trough of the waves. In deep water all the expressions gave the same olose agreement. In shallow water for waves of appreciable steepness, Equation (2) (linear theory) compares more closely to the experimental results than the second approximation of the Stokes wave theory.

The seoond approximation (Stokes) to the vertical particle velooity $(1$ ) ( $\nabla$ in ft. (sec.) is given by the expression

$\nabla=\frac{\pi H}{T} \frac{\sinh \frac{2 \pi S}{L}}{\sinh \frac{2 \pi d}{L}} \sin \frac{2 \pi}{L}(\bar{x}+x-o t)+\frac{z}{4} \frac{\pi^{2} H^{2}}{L T} \frac{\sinh \frac{4 \pi S}{L}}{\left(\sinh \frac{2 \pi d}{L}\right)} \sin \frac{4 \pi}{L}(\bar{x}+x-o t)$

which for the mean verivioal particle position becomes

$$
\nabla= \pm \frac{\pi \mathrm{H}}{\mathrm{T}} \frac{\operatorname{Sinis} \frac{2 \pi S}{\mathrm{~L}}}{\operatorname{Sint} \frac{2 \pi d}{\mathrm{~L}}}
$$

This result is oommon to beth the first and second approximations in deep or ohallow water.

The seoond approximation (Stokes) to the horizontal particle position $(1,2)$ in its orbit with no mass transport is given by the expression

$x=\frac{-H}{2} \frac{\operatorname{Cosh} \frac{2 \pi S}{L} \operatorname{Sinh} \frac{2 \pi \mathrm{Q}}{L}}{L} \frac{2 \pi}{L}(\bar{x}-\infty t)-\frac{\pi H^{2}}{4 L\left(\operatorname{Sinh} \frac{2 \pi \mathrm{L}}{L}\right)^{2}}\left[-\frac{1}{2}+\frac{3}{4} \frac{\operatorname{Cosh} \frac{4 \pi S}{L}}{\left(\operatorname{Sinh} \frac{2 \pi d}{L}\right)^{2}}\right] \sin \frac{4 \pi}{L}(\bar{x}-0 t)$ 
Where $S$ for this case is the mean partiole elevation above the bottom, (ft.) Equation 8 seems almost entirely inadequate for all but a few values of d. In deep water and for better agreement in shallow water the equation was $\overline{\mathrm{L}}_{\mathrm{re}}$ duoed to

$$
x=-\frac{H}{2} \frac{\cosh \frac{2 \pi S}{L}}{\operatorname{Sinh} \frac{2 \pi d}{L}} \sinh \frac{2 \pi}{L}(\bar{x}-o t)
$$

The seoond approximation (Stokes) to the vertical particle position $(1,2$ ) in its orbit is given by the expression

$y=\frac{H}{2} \frac{\sinh \frac{2 \pi S}{L}}{\sinh \frac{2 \pi d}{L}} \cos \frac{2 \pi}{L}(\bar{x}-o t)+\frac{3}{16} \frac{\pi \mathrm{B}^{2}}{L} \frac{\sinh \frac{4 \pi s}{L}}{\left(\operatorname{Sinh} \frac{2 \pi d}{L}\right)^{4}} \cos \frac{4 \pi}{L}(\bar{x}-o t)$

For shallow water Equation (10) beoomes inadequate and better results were obtained when it was reduoed to the following expression

$$
y=\frac{H}{2} \frac{\sinh \frac{2 \pi S}{L}}{\sinh \frac{2 \pi d}{L}} \cos \frac{2 \pi}{L}(\bar{x}-o t)
$$

The sign, sine, and oosine convention used in the above equations are consistent with the figures presented in the report and may vary slightly from some of the referenoes.

Results and Disoussion: The experimental results are presented in graphioal form. A sumary of the wave conditions oovered is presented in Table I. Figures 1 to 5 oover the oonditions of d greater than about 0.2. Figures 6 to 10, and 17 to 25 oover the oonditions of $\frac{d}{\mathrm{~L}}$ less than 0.20 . Figures 11 to 16 cover the oase of breaking waves on sloping beaches. Since there oan be no abrupt ohange from good agreement to bad agreement, Figures 5, 6 and 17 where values of d/s range between 0.20 to 0.10 may be classed as the region where the Stokes theory deviates $20 \%$ or more from the measurements for waves of appreoiable steepness.

Plgure 1 shows a very steep, deep-water wave $(\alpha / 2=0.556)$ where the theoretioal results for the second approximation of the Stokes theory are approximately the same as for the first approximation. The maximum error between the theory and measurements is about $20 \%$ based on the measured results. The partiole path for this wave oondition is almost exaotly a cirole. Figure 2 where $d=0.449$ is almost identioal with $F_{1}$ gure 1 , but with a wave that is somewhat less stoep. Figure 3 shows a relatively steep wave in water that is relatively shallow $(d / L=0.238)$. The theoretioal horizontal partiole velocity shows the variation between the first and sesond approximations. The agreement between measurement and theory is generally within $20 \%$ based on the measured results for this oase. Pigure $4(\mathrm{~d} / \mathrm{h}=0.228)$ is almost identioal with Figure 3 . The particle path in this oase is now elliptionl. 
Figure 5 shows a very steep wave in relatively shallow water (d/L $=0.191$ ) and is an example of the beginning of the deviation of the second approximation. The surface time history has a definitely flat trough for more than $60 \%$ of the wave oycle which is characteristic of shallow water waves of appreciable steopness. Tre horizontal particle velocity distribution shows less curvature than the steop wave shown in Figure 10 The data presented thus far on horizontal particle velooity indicate that the particle velooity at a given elevation above the bottom is the same magnitude under the crest as under the trough. The second approximation of the Stokes theory indicates that the variation between the trough horizontal particle velocity and the crest velocity at the same level should be about $20 \%$. The point has now been reached where the difference between the first and seoond approximation is about the same as the differenco between the measurements and the Stokes theory so that waves in more shallow water can be expocted to show even greater variation between theory and measurement. For this example (Figure 5) the particle path is elliptical but is more rounded at the crest and flattened at the trough both in measurement and theory indicating typical shallow water effects. Another example of a wave in the same range is shown in Figures 6 and 17. This wave would not be considered steep in deep watss, but it is a steop wave in this relatively shallow water $(d / L=0.110)$. The wave surfaco time history and horizontal particle velocity shows good agreement with the theory but in the latter case a definite increase in the difference between crest and trough velooity at the same level is shown.

Remaricably good agreement between the measured vertical partiole velocity and the theoretioal results is shown in Figure 17 for this wave condition. In the Figures 6 and 17 and in the following Figures 7 to 10 and 18 to 25, the waves were made as steep as possible for the shallow water condition presented.

Figures 7,18 and 22 shows a relatively steep wave in relatively shallow water $(d / L=0.079)$ which is definitely beyond the region of good agreement. Any agreement of the measurements with the theory probably is more coincidental than anything else. For instanoe, the secondary wave shown in the theoretical profilo of the second approximation ( $F i$ gure $7 a$ ) is for a wave of permanent form, but the measured wave does not have a permanent form since the secondary wave is traveling at a different velooity than the large wave. The agreement between horizontal partiole velooity and the theory is poor; however, there is oonsiderable experimental soatter in this example (Figure $7 \mathrm{~b}$ ). Figures $70,22 \mathrm{a}$, and $22 \mathrm{~b}$ show fairly olose agreement between theory and measurement, but the theory is a mixture of the first and second approximations. The first approximation is used in the $x$ direotion and the second approximation is used in the y-direction. Although the agroment is good, this approach is arbitrary in that using one approximation or the other dopends upon a chosen $d / L$ without any rules for this chosce. If the second approximation is used in the $x$ direction, the theoretical curve extends beyond the borders of the graph. The first approximation in the y-direction, if used alone, would mean a symmetrical orbit about $y=0$. In Figure 18, the theory has departed considerably from the measured values of the vertical particle volocity. The wave illustrated in Figures 8,19 and 23 is in slightly more shallow water $(d / L=0.057)$ than the wave of Figures 7 , 18 and 22 , but is otherwise 1dentiogl. The theoretical surface time history differed so greatly from the measurements that it was considered not to apply and was not shown. In Figures 8b, 8c, 23a and 23b, only the first approximation was used and showed better agreement to the measurements than the second approximation which oould not be oontained within the graph. This close agreement of the first approximation is contradiotory to the theoretioal approaoh indioated in that the 
second approximation should for all cases be botter than the first approximation. Figure 19 of the vertical particle velooity for this wave shows that the theory lays within the experimental scatter.

The wave condition $\left(\frac{d}{L}=0.044\right)$ of Figures 9,20 and 24 , and the wave condition $\left(\frac{d}{d}=0.035\right)$ of Figures 10,21 , and 25 show such poor agreement with the Stokes wave theory that the theoretical curves could not be contained within the limits of the graphs except for the horizontal and vertical partiole velocities. In Pigure 10a, a secondary wave is shown traveling at almost half the velocity of the larger wave. In Figures 100 and 25 , the secondary wave appears as an inner loop in the particle orbit. In Figure $9 a$, a slight secondary wave was shown and this causes the hesitan partic le motion shown at the right side of Figures 90 and 24. In Figures $9 \mathrm{~b}$ and $10 \mathrm{~b}$, the horizontal particle motion under the trough is definttely less than the particle velocity under the crest. Rurther, the meximum horizontal particle velocity at the orest of the wave has not begun to approach the order of magnitude of the wave velocity.

The experimental results of the breaking waves on a sloping beach and the experimental results of the waves in very shallow water show that the trends of the water particie motion of the shallow water waves are continued when the wave breaks. The breaking waves presented are classified by the beach slope and their deep-water steepness. Two beach slopes ( $1: 10$ and $1: 50$ ) were selected as about representative of the two extremes possible in the model. From the model

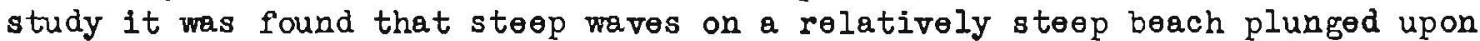
breaking while low waves spilled upon breakinge on a flat beach, the steep waves form spilling breakers and the low waves form plunging breakers. Figure $l 1$ is an example of a very low wave on a steep beach. The surface time history is asyrametrical and very irregular. The irregular waves in the trough are traveling seaward. In Figure Ila, the surface time history and the space profile show good agreement over a distance of $20 \%$ of the wave length on either side of the crest. The horizontal particle velooity at the orest is approximately twice that at the bottom. However the maximum particle velocity under the trough is the same as under the crest at the same levelo The maximum particle velocity. near the orest is not as great as the wave velocity. The particle motion including mass transport is very irregular: however, it was observed within a relatively narrow region of the breaker that the maximum vertical partiole velocity accurred as the wave crest approarhed and the maximum horizontal velooity osourred when the wave broke, even though the particle was not directly under the breaking crest. That is, the maximum horizorital particle veloeity occurred at a position other than the maximum elevation in the orbit if the particle was not direotly under the crest when the ware broke. Hence for such particles that were seaward of the breaker the maximum herizontal velocity occurred slightly afterward or exactly as the wave crest passod. For particles that were shoreward of the breaker maximum horizonte 1 velcaity occursed before the crest passed (foem line). The wave condition of Figure 12 is identical to that of Figure 11 except that the wave is steeper in deep water. For this wave the horizontal particle velooity at $\operatorname{th} \theta$ orest is nearly the same as the wave relocity. Figure 13 shows a stoop wave on a steep beach. This is the only breaking wave for which the stokes theory was containes within the borders of the graph. Agreement between the breaker and the theory was not expected but it is interesting to $f$ ind fair agreament as to the order of magnitude which was found for this case alone. Espooially signifioant is that the horizontal particle velocity under the orest and trough are equal at equal levels. Hence sterp waves on steep berohes behave more like waves in relatively deep water of constant depth than any other waves on sloping beaches. This is apparent if the facts are considered that a steop wave oannct shoal vory much without breaking and that waves shoal rapidily in a short distanoe on steep beaches. Thus a steep wave on a steep beach cannot change much in shape before breaking。 
Plgure 14 shows a low wave on a flat beach. The surface time history is flat and long in the trough which is typical of very shallow-water waves. The horicontal particle velocity is typioal of very shallow-water waves in that the velooity under the crests is about twice the particle velocity under the trough. The meximum particle velocity near the orest is nearly equal to the wave velocity. The partiole path shows the very slow and hesitant motion of the trough set off from the very rapid motion as the crest passes and breaks. Figure 15 is a slightly steoper wave than Figure 14 but is otherwise identioal. Figure 16 is that of a very steep wave on a flat beach. Again the phenomenon of Figure 13 is repeated. The profile is more symmetrioal. The particle velocities under the orest and trough are equal. In this oase the partiole path is more regular or uniform. In Figure 150 and $16 \mathrm{~b}$, the maximum horizontel particle velocity near the orest is only half the wave velocity at breaking. This is ovidence that only the slightest amount of water at the orest of the waves ever attains the velooity of wave propagation even at the breaking point. Figures lla to 16a all showed that the surface time history $(x=0)$ passed the breaking point and the space profile $(t=0)$ show close agreement over a distance of about $20 \%$ of the wave length on either side of the breaking point.

Conolusions: The Stokes wave theory to the seoond approximation was compared to a wide range of model wave conditions. The waves were uniformly generated and progressed over constant depths and sloping beaches. Fran observation and oomparison the following oonclusions seem justifieds

1. The theory and measurement for surface time histories or profiles, for vertioal and horizontal particle velooities, and for particle orbits show a greement within $20 \%$ (based on the measured data) for all waves where $\frac{d}{\mathrm{~L}}>0.2$.

2. There existsa range of $\frac{d}{L}$ between 0.2 and 0.1 where the theory shows fair agreement with the measurements ${ }^{\mathrm{L}}$ of waves with appreciable steepness.

3. Where $\frac{d}{\mathrm{~L}}<0.1$, the theory does not agree with the measurements

either for waves in oonstant depth or for waves breaking on sloping beaohes. It was not expeoted that the theory would oompare with these very shallow-water maves.

4. In deep and relatively doep water the horizontal partiole velooity under the crest and under the trough are equal in magnitude at the same elevation above the bottom. In shallow water the horizontal partiole velocity under the orest may be about twice the magnitude as the partiole velooity under the trough at the same level. Very steep waves on sloping beaches are similar to deepwater waves in regard to the faot that the horizontal partiole velooity under the orest and trough are equal at the same level. Low waves on a low beach are similar to very shallow water waves in this respeot.

5. The maximum horizontal particle velooity at the orest of the wave may attain the wave velocity of propagation as the wave breaks but this phenomenon is confined to a very narrow region of water at the arest of the ware. 
6. Waves in very shallow water that form secondary waves are not waves of permanent form. The seoondary wave travels at a velooity which is less than the velocity of the original wave train. The seoondary wave causes a second loop in the partiole orbit.

7. The surface time history and the spaoe profile are nearly identioal within a distanoe of about $20 \%$ of the wave length on either side of the crest of a breaking wave.

8. The maximum vertical partiole velocity ocours at the mean partiole position $(y=0)$. In the case of breaking waves on sloping beaches, the greatest maximum vertioal velocity occurs as the wave orest approaches. The maximum horizontal partiole velocity occurs under the crest when the wave passes or breaks. However, the maximum horizontal particle velocity may occur slightly before or slightly after the particle reaches the maximam elevation in its motion, that is slightly before or after the wave orest passes, depending on whether the particle is shoreward or seaward, respeotively, of the breaker.

\section{$\underline{R e f e r e n o \theta s}$}

(1) Stokes, G. G. "On the Theory of Osoillatory Waves", Trans. Cambridge Philosophioal Society, Vol. VIII, p. 441, 1947.

(2) Wiegel, R. L., and J. W. Johnson. "Elements of Wha Theory", Proceedings of First Conferenoe on Coestal Enginerring, 1951, Council on Ware Researoh, The Engineering Foundation.

(3) Beach Erosion Board. "A Summary of Progressive Osoillatory Waros in Water", Teoh. Report No. 1, 1941, Corps of Engineers, Wa,sh. D.C.

(4) Beaoh Erosion Board, "A Sumary of the Theory of Osoillatory Waves", Teoh. Report No. 2, 1942, Corps of Engineers, Wash. D.C. 
Table I

Sumary of Average Wave Conditions

Part Is Unbroken waves of oonstant helght and perlod

\begin{tabular}{|c|c|c|c|c|c|c|c|c|}
\hline Fig. No. & $\begin{array}{l}\text { II } \\
\text { ft. }\end{array}$ & $\begin{array}{l}\text { I } \\
\text { ft. }\end{array}$ & $\begin{array}{c}T \\
\text { seo. }\end{array}$ & $\begin{array}{c}c \\
\mathrm{ft} / \mathrm{s} \theta 0\end{array}$ & $\begin{array}{c}\text { d } \\
\text { ft. }\end{array}$ & $\mathrm{H} / \mathrm{L}$ & $d / L$ & $\begin{array}{l}\text { Bottom } \\
\text { Slope }\end{array}$ \\
\hline 1 & 0.362 & 3.76 & 0.87 & 4.34 & 2.09 & 0.096 & 0.556 & Hor. \\
\hline 2 & 0.146 & 2.71 & 0.74 & 3.69 & 1.218 & 0.054 & 0.449 & 1,50 \\
\hline 3 & 0.065 & 1.23 & 0.50 & 2.35 & 0.292 & 0.053 & 0.238 & Hor. \\
\hline 4 & 0.297 & 5.17 & 1.06 & 5.06 & 1.181 & 0.057 & 0.228 & $1: 50$ \\
\hline 5 & 0.469 & 5.42 & 1.22 & 4.44 & 1.035 & 0.087 & 0.191 & Hor. \\
\hline 6 & 0.099 & 2.66 & 0.92 & 2.54 & 0.292 & 0.037 & 0.110 & Hor. \\
\hline 7 & 0.150 & 3.71 & 1.30 & 3.02 & 0.292 & 0.031 & 0.079 & Hor. \\
\hline 8 & 0.105 & 5.10 & 1.62 & 3.24 & 0.292 & 0.021 & 0.051 & Hor. \\
\hline 9 & 0.131 & 6.58 & 2.11 & 2.99 & 0.292 & 0.020 & 0.044 & Hor. \\
\hline 10 & 0.126 & 8.32 & 2.67 & 3.51 & 0.292 & 0.016 & 0.035 & Hor \\
\hline
\end{tabular}

Part II Breaking waves of oons tant period

\begin{tabular}{|c|c|c|c|c|c|c|}
\hline FIg. No. & $\begin{array}{l}E_{B} \\
\text { ft. }\end{array}$ & $\begin{array}{c}\mathrm{T}_{\mathrm{B}} \\
\mathbf{s e o}\end{array}$ & $\begin{array}{c}C_{B} \\
f t / s 00 .\end{array}$ & $\begin{array}{l}\mathrm{d}_{\mathrm{B}} \\
\mathrm{ft.}\end{array}$ & $\mathrm{H}_{0} / \mathrm{L}_{0}$ & $\begin{array}{l}\text { Bottom } \\
\text { Slopo }\end{array}$ \\
\hline 11 & 0.24 & 2.50 & 3.45 & 0.252 & 0.0036 & 1,10 \\
\hline 12 & 0.37 & 1.51 & 4.65 & 0.300 & 0.0206 & $1: 10$ \\
\hline 13 & 0.35 & 1.00 & 3.55 & 0.423 & 0.0797 & 1.10 \\
\hline 14 & 0.264 & 2.62 & 3.80 & 0.297 & 0.0037 & 1,50 \\
\hline 16 & 0.276 & 1.41 & 4.00 & 0.330 & 0.0262 & $1: 50$ \\
\hline 16 & 0.183 & 0.78 & 3.50 & 0.230 & 0.0778 & 1.50 \\
\hline
\end{tabular}




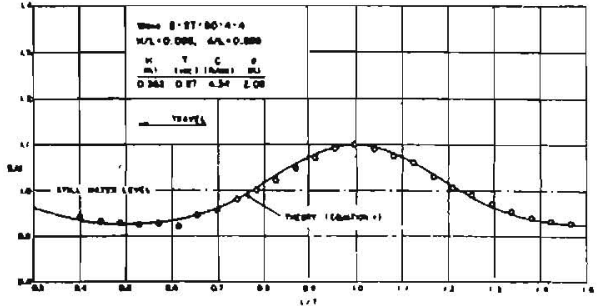

i

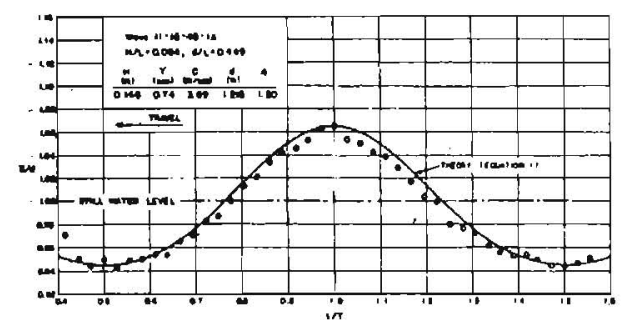

1
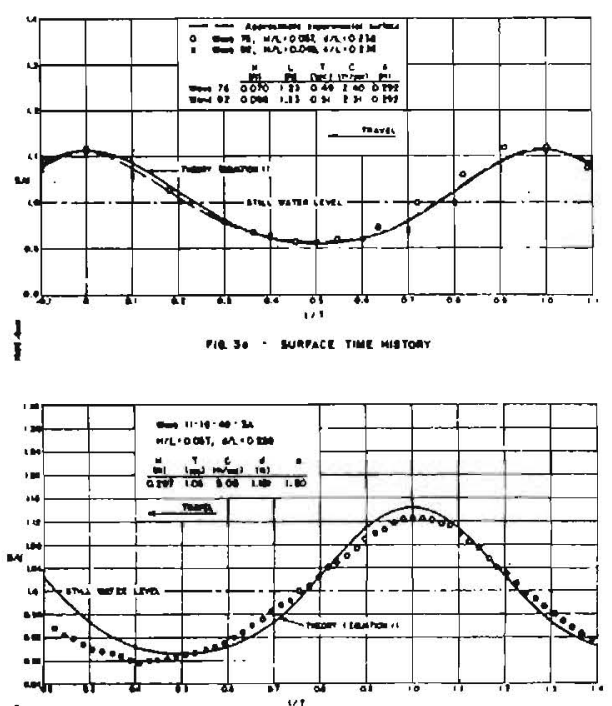

i

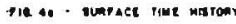
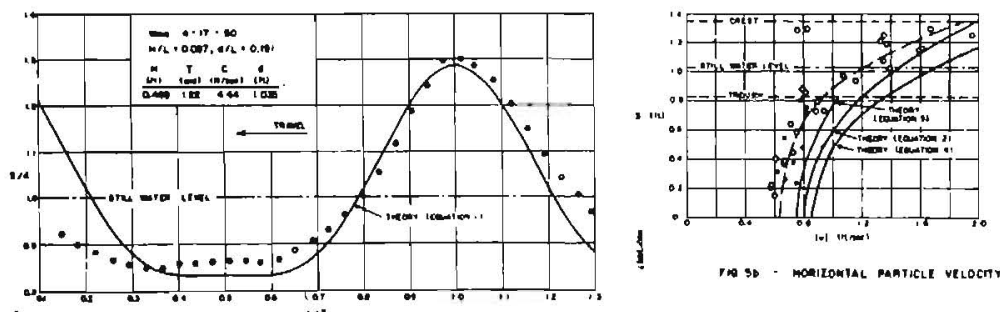

$-\cdots=$

$\because: 0 \infty$

sing

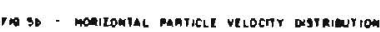

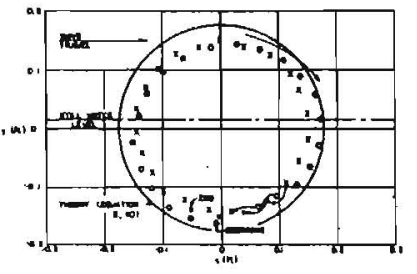

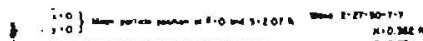

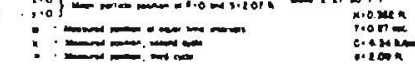

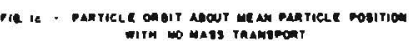

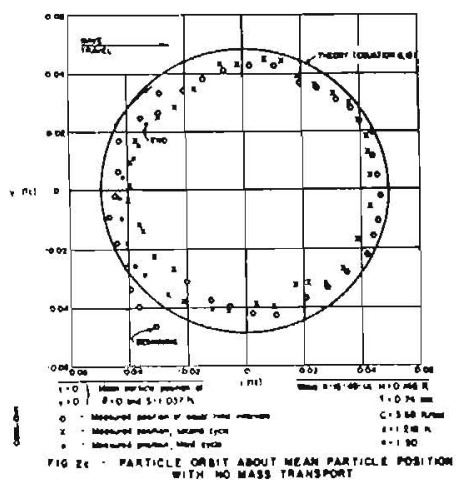

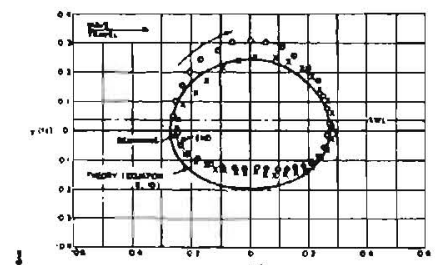

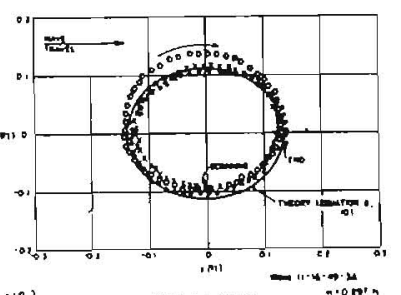

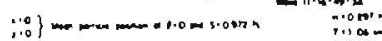

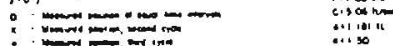

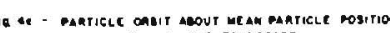

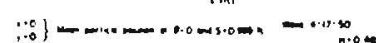

:

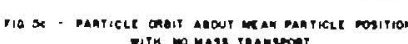

FIGURES $10-5$ 

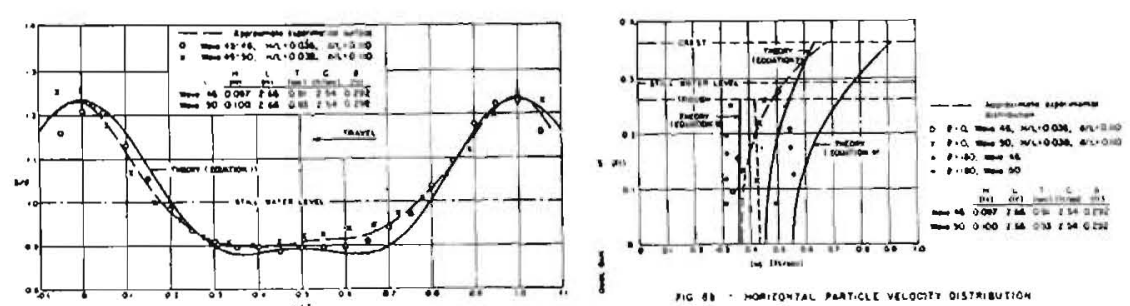

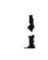
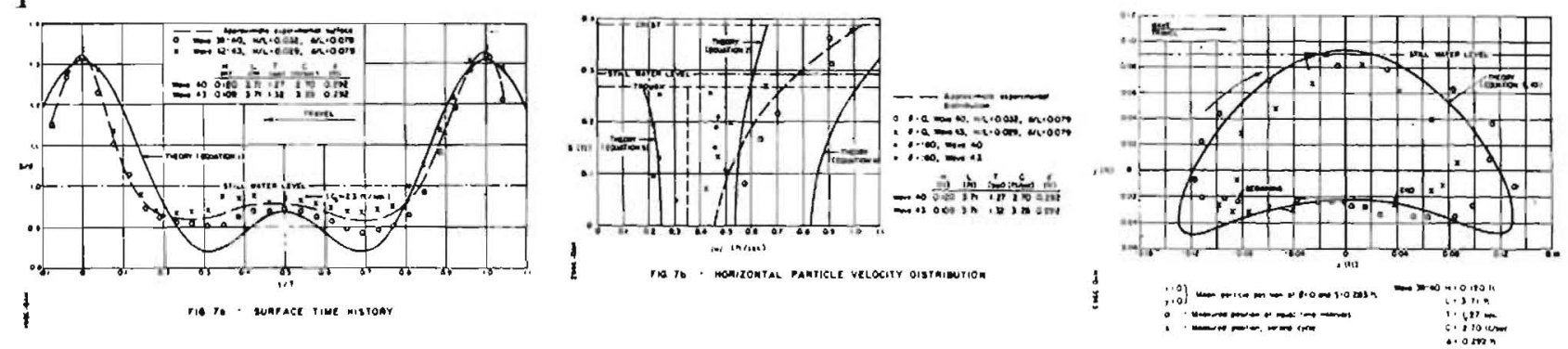

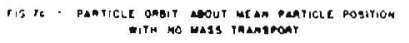
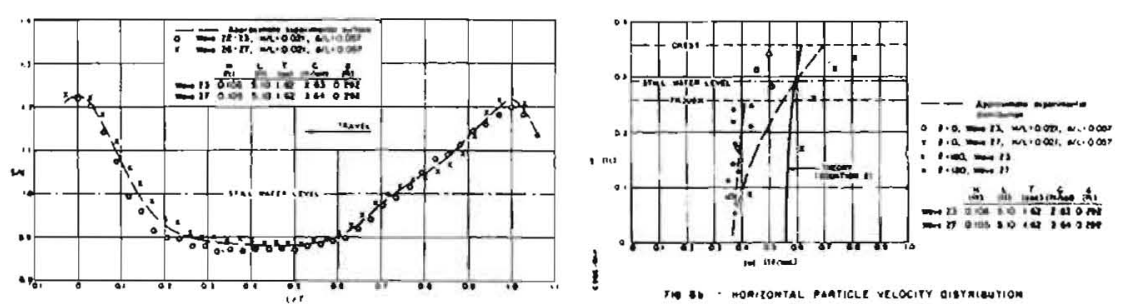

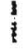

fig as - sunsace tive mogront
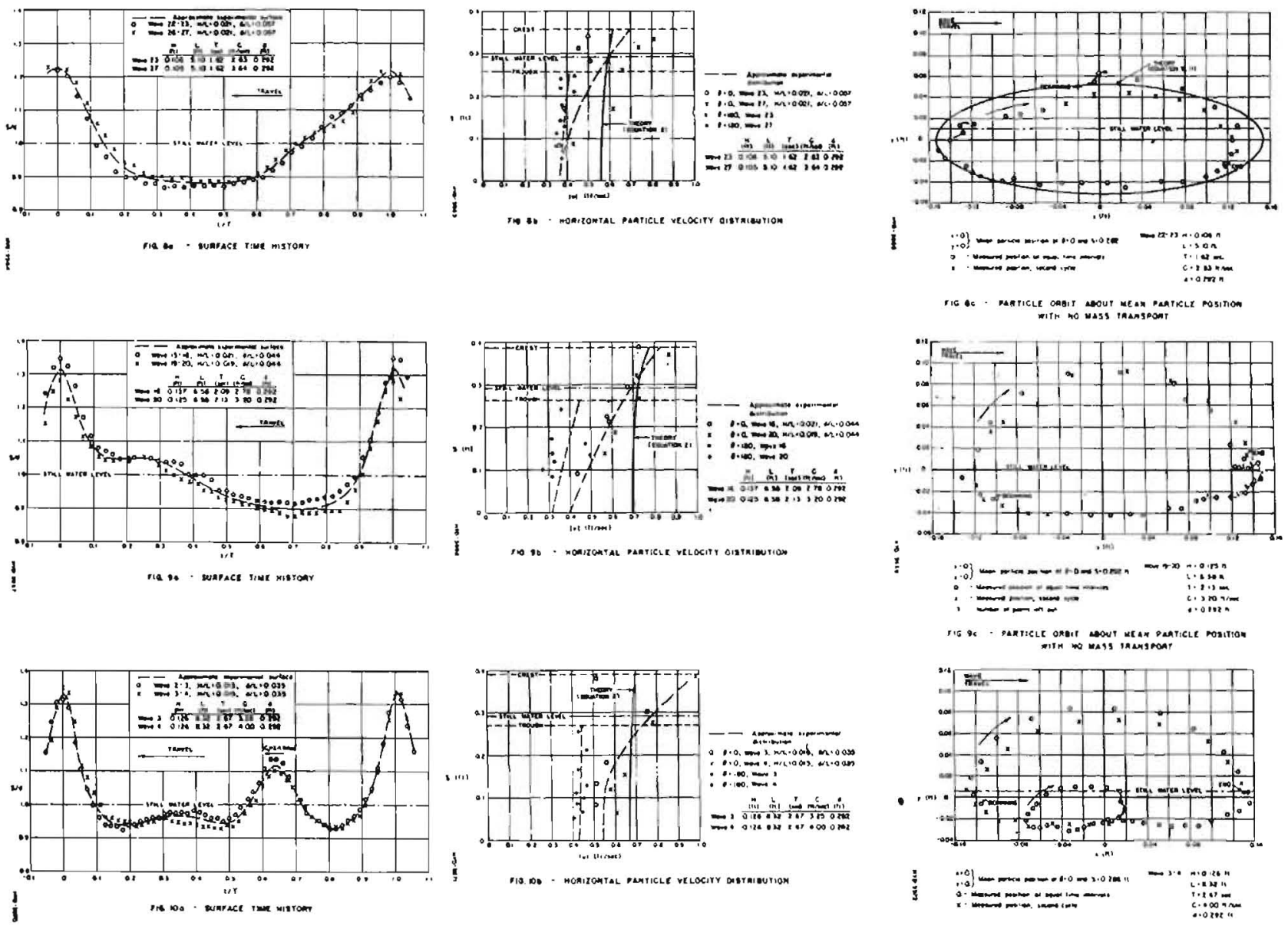

$\stackrel{d}{\vdots}$
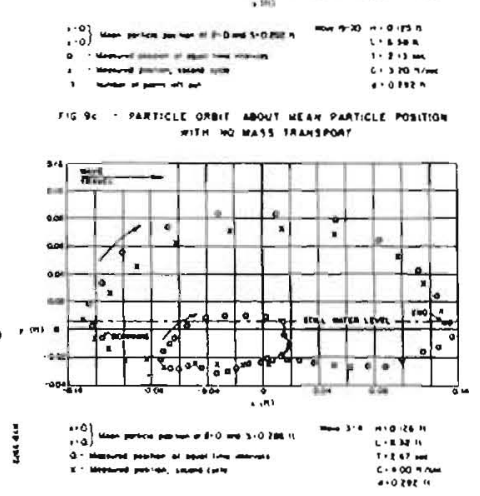

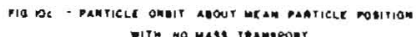

FIGURES $60-10$ 

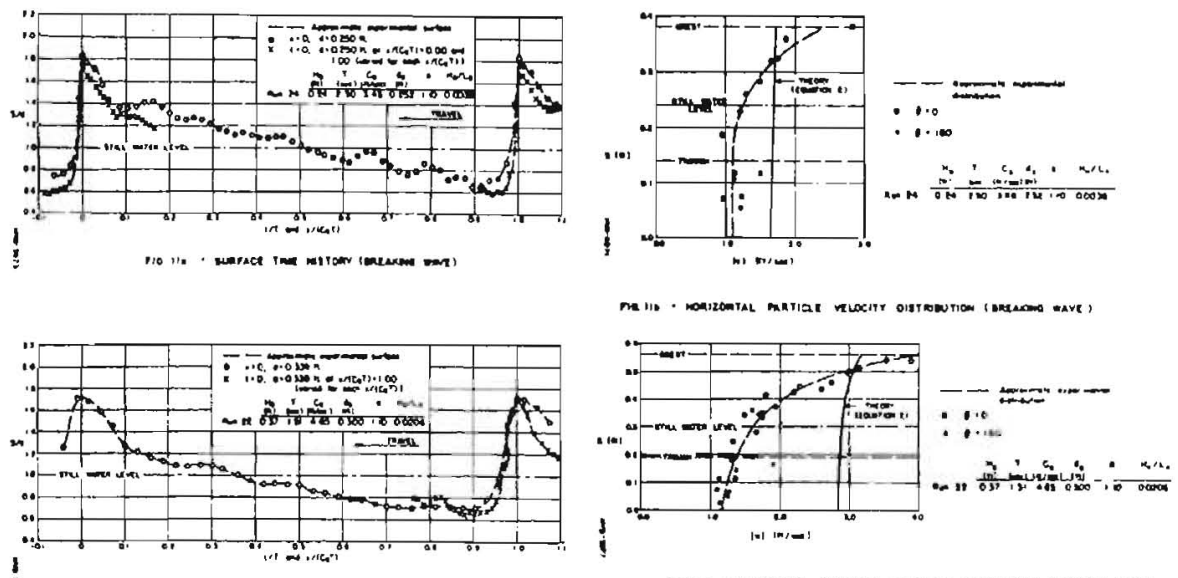

i

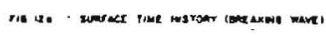
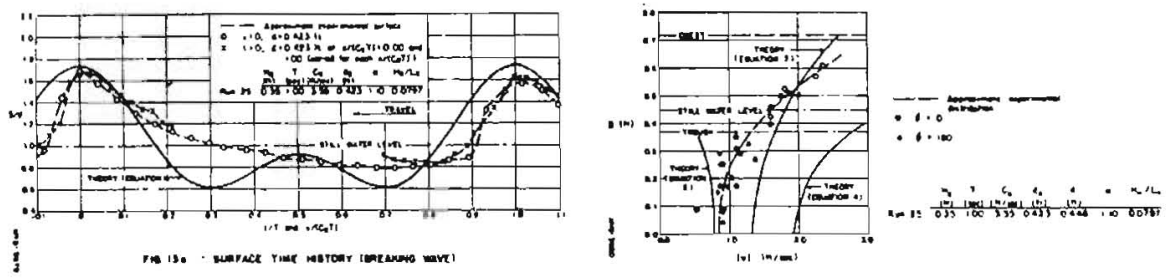

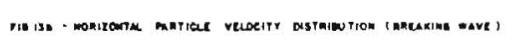
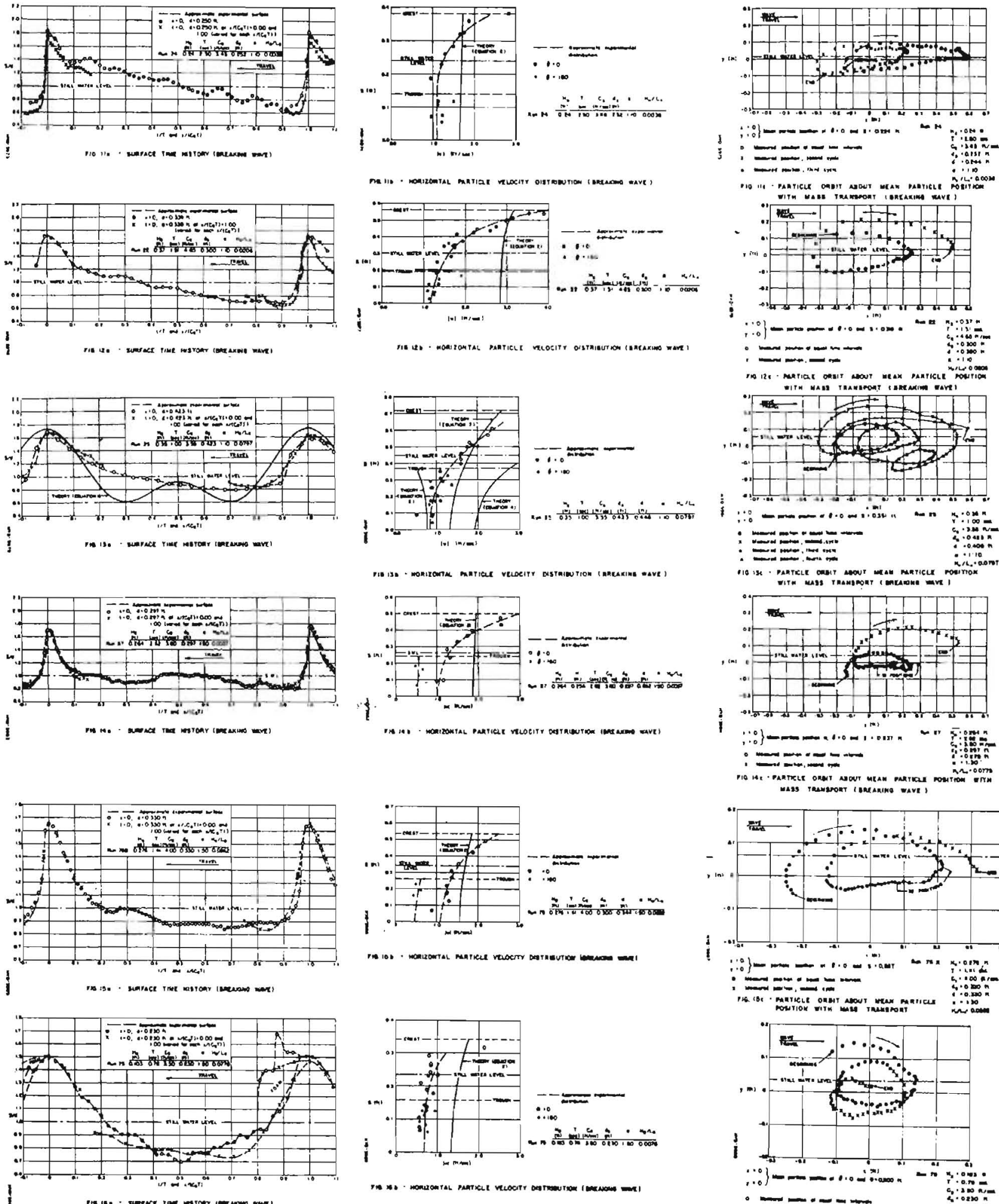

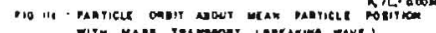
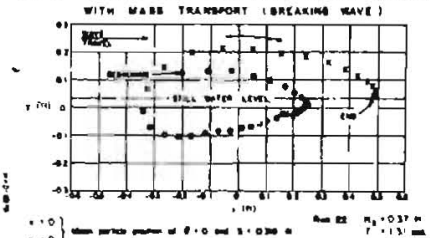

-

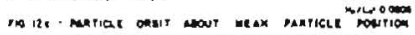

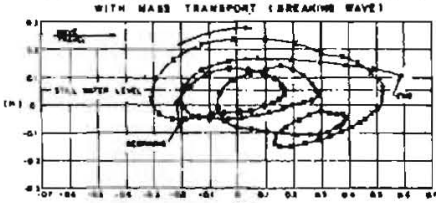

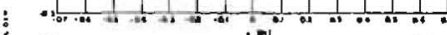

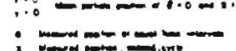

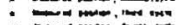

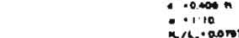

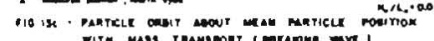

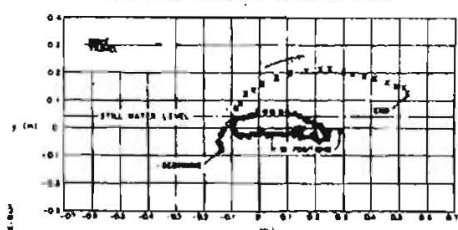

i

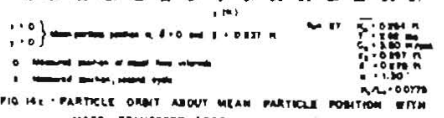

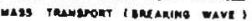

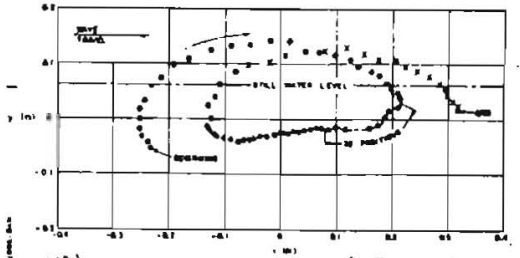

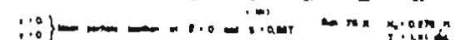

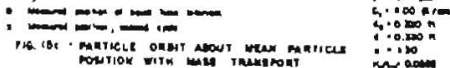

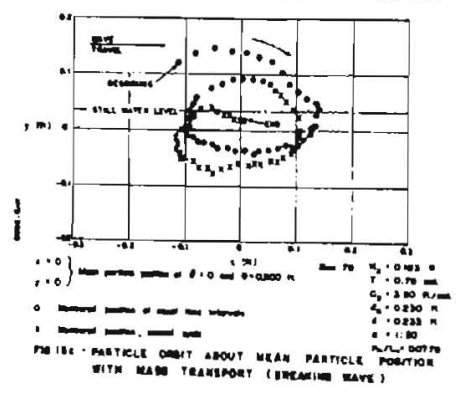

FIGURES Ito-16e 


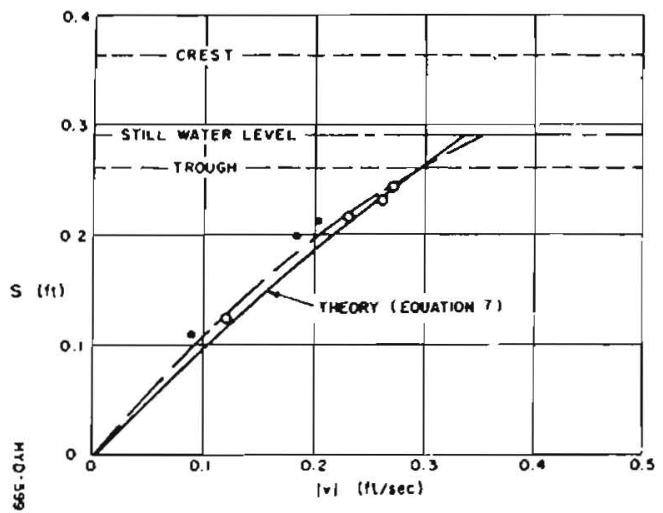

- Approximate experimental

- $\theta .90^{\circ}$. $46, H / L=0.036, d / L=0.110$ - $\theta=270^{\circ}$, wave 46

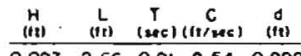

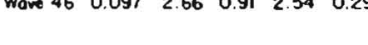

FIG. 17 - VERTICAL PARTICLE VELOCITY DISTRIBUTION

$\bar{\omega}$
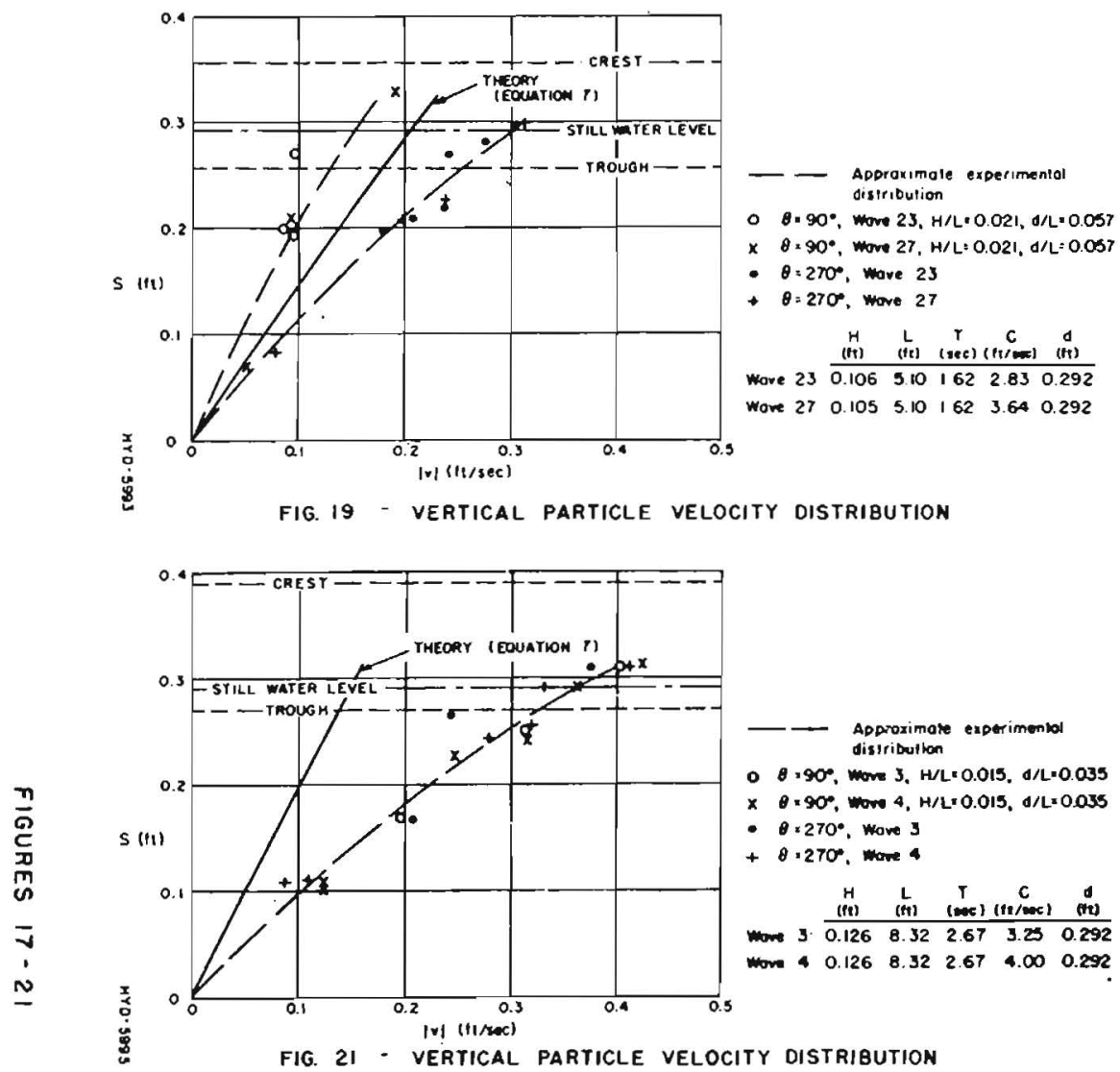
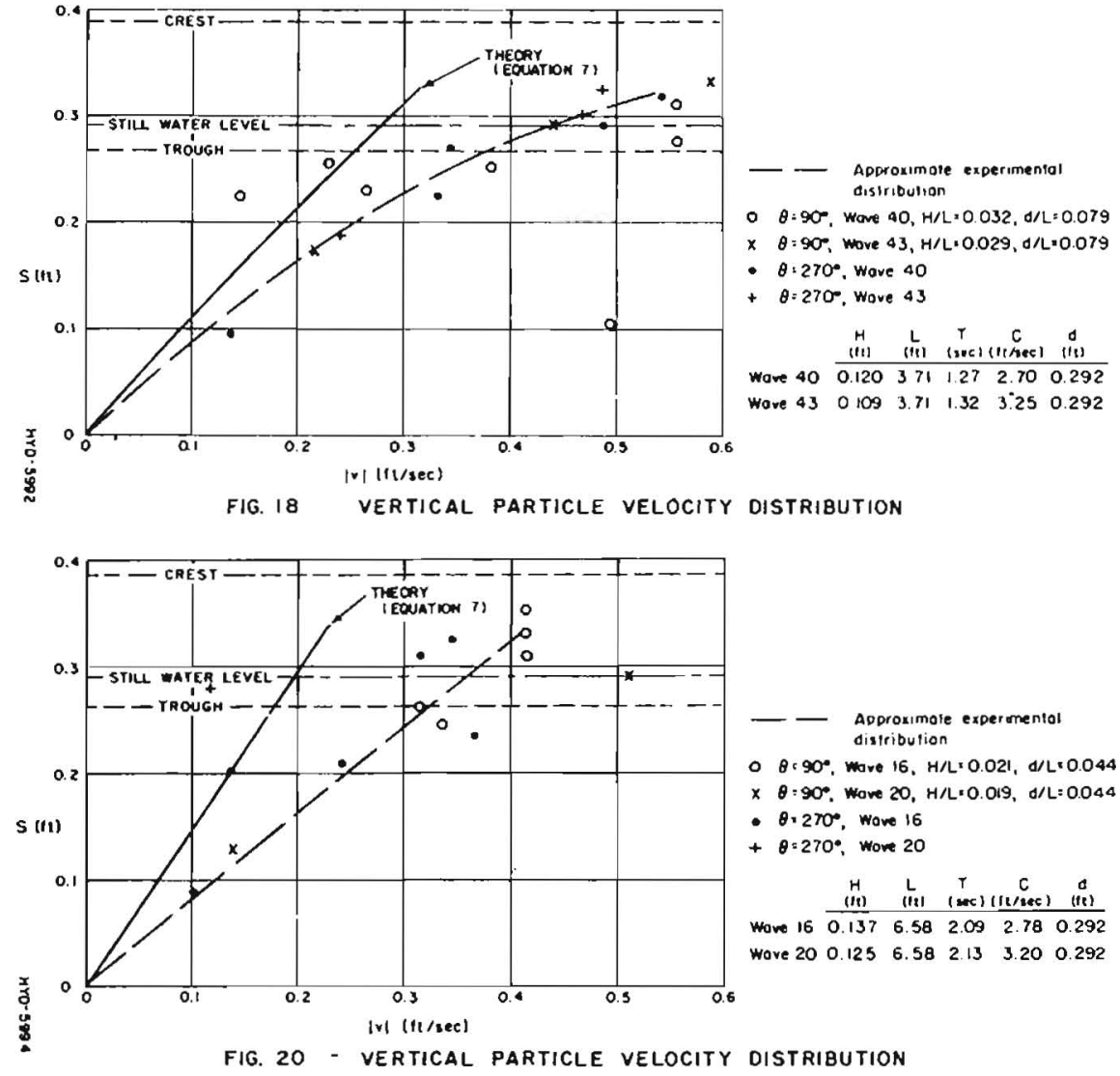

FIG. 20 - Vertical PARTICLE VELOCITY DISTRIBUTION 


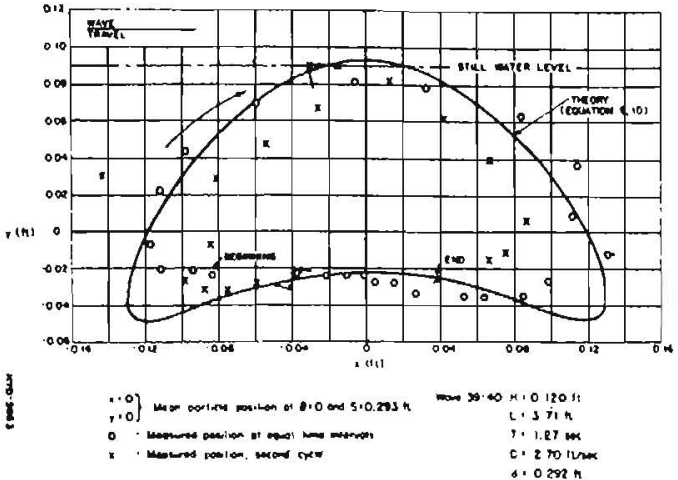

FIa 280 - PARTICLE ORBIT ABOUT MEAN PARTICLE POSITION WITH NO MASS TRAKSPORT

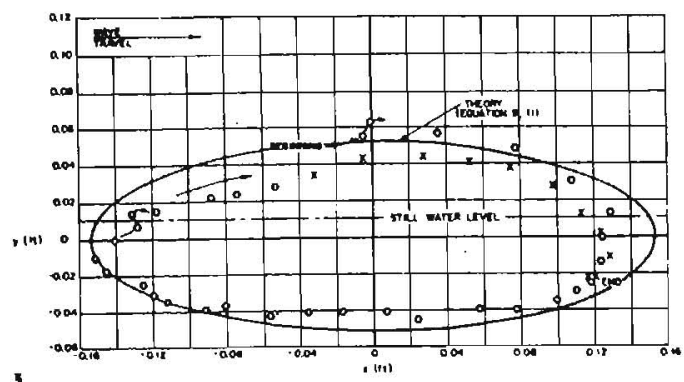

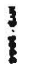

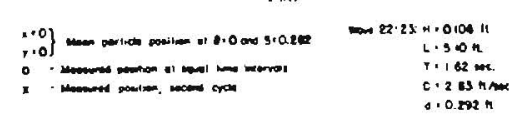

10. 23a - PARTIELE ORBIT ABOUT MEAN PARTICLE POSITIOM WITH MO MASS TRAMSPORT

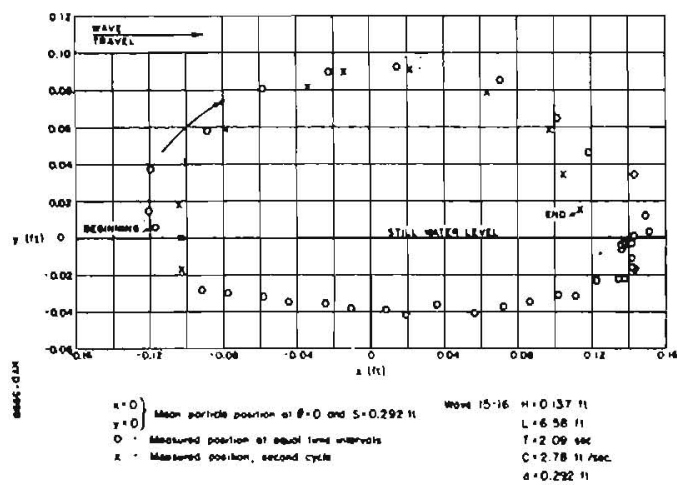

F10. 240 - PAATICLE ORgir about MEAM PARTICLE position WITH MO MASS TRAHSPORT

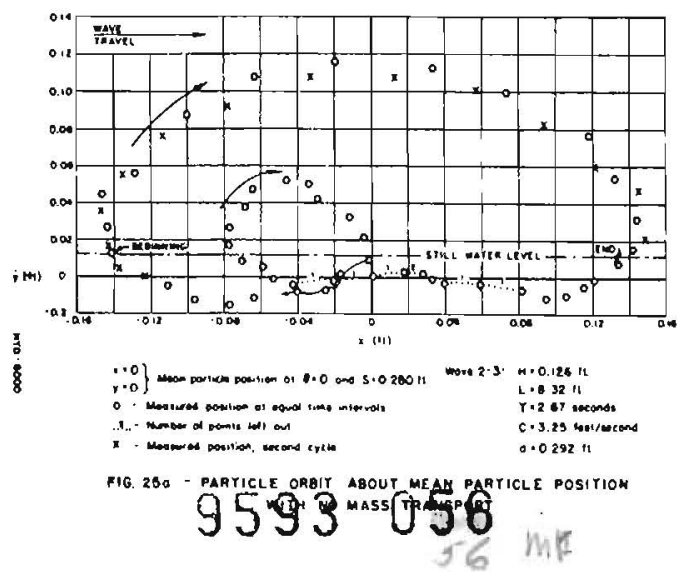

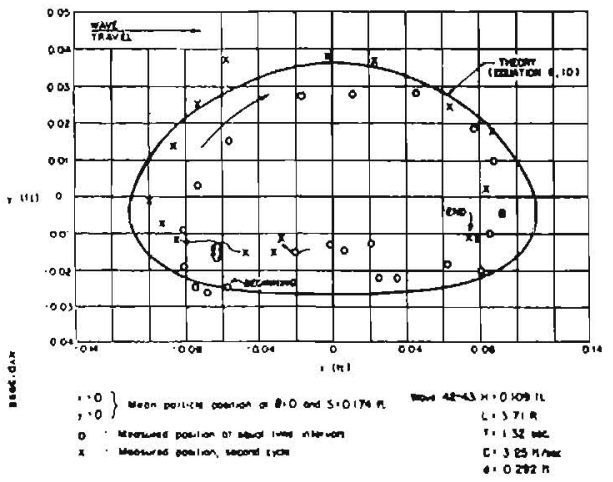

TIG 22D- PARTIGLE ORBIT ABONT MEAM PARTICLE POSITION WITH MO MASS TMAMSPORT

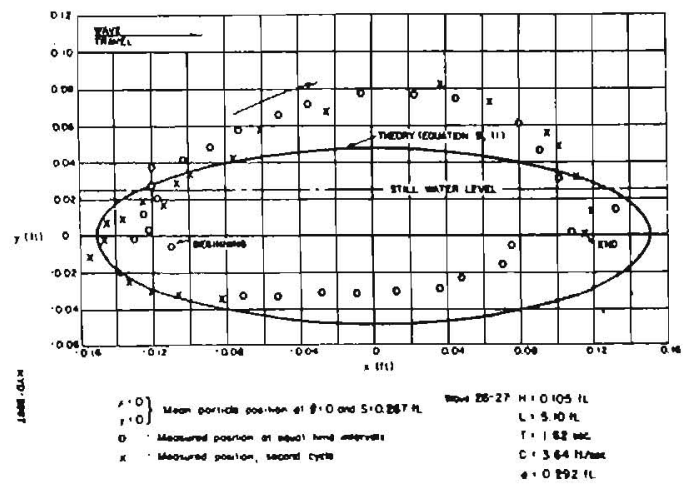

IIO 23 D - PARTICLE ORBIT aBout MEAN PARTICLE POSITION WITH KO MASS TAANSPOART

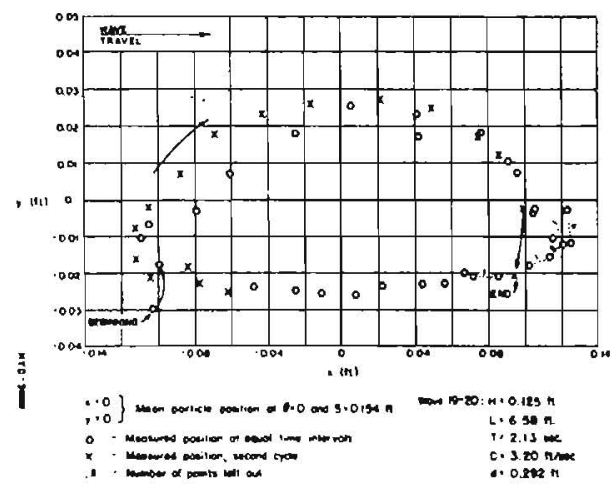

FIQ 24D - PARTICLE ORGIT ABOUT UEAN PARTICLE POSITIOA WITM MO MASS TRAKSPORT

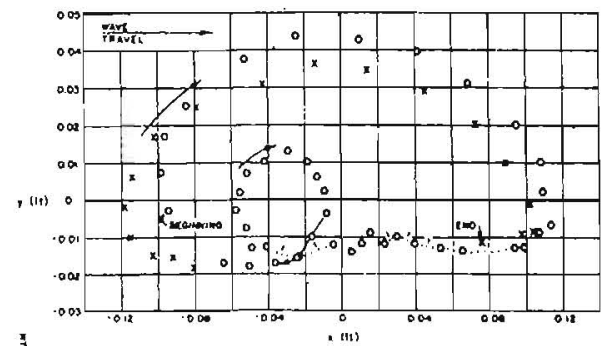

$\frac{\pi}{d}$

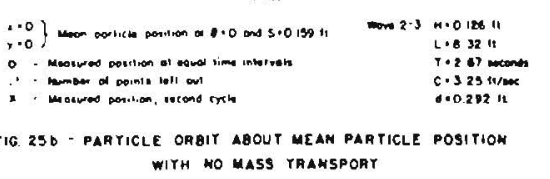

FIGURES $220-25$

D 67290 